\title{
Rural-Focused Nursing Education: A Summative Evaluation of RNs' Experiences of the Rural Nursing Certificate Program
}

\author{
Martha MacLeod \\ University of Northern British Columbia, martha.macleod@unbc.ca \\ Jessica Place \\ University of Northern British Columbia, jessica.place@unbc.ca
}

Follow this and additional works at: https://qane-afi.casn.ca/journal

Part of the Educational Assessment, Evaluation, and Research Commons, and the Nursing Commons

\section{Recommended Citation}

MacLeod, Martha and Place, Jessica (2015) "Rural-Focused Nursing Education: A Summative Evaluation of RNs' Experiences of the Rural Nursing Certificate Program," Quality Advancement in Nursing Education - Avancées en formation infirmière: Vol. 1: Iss. 2, Article 3.

DOI: https://doi.org/10.17483/2368-6669.1029

This Article is brought to you for free and open access by Quality Advancement in Nursing Education - Avancées en formation infirmière. It has been accepted for inclusion in Quality Advancement in Nursing Education - Avancées en formation infirmière by an authorized editor of Quality Advancement in Nursing Education - Avancées en formation infirmière. 


\section{Rural-Focused Nursing Education: A Summative Evaluation of RNs' Experiences of the Rural Nursing Certificate Program}

\section{Cover Page Footnote}

This project was a collaboration with, and under the auspices of, the Chief Nursing Officer Council of British Columbia originally led by Suzanne Johnston (Northern Health) and Tom Fulton (Interior Health). We gratefully acknowledge the support and participation of British Columbia's health authorities, which has been vital to the success of the Rural Nursing Certificate Program. The authors would also like to acknowledge Monica Adamack, Norma John and Elizabeth Lindsay for the vital role they each played in the implementation and evaluation of the Rural Nursing Certificate Program. The BC Ministry of Health Nursing Directorate provided funding for this project. 


\section{Introduction}

Registered nurses (RNs) working in rural and remote communities perform multidimensional and complex roles requiring "considerable depth and breadth of knowledge" (MacLeod, 1998, p.iii). MacLeod and Zimmer (2005) have described how, on any given shift, a rural nurse might encounter a number of scenarios from motor vehicle accidents and mothers in labour to psychiatric crises and children with fevers. In addition, the context of rural nursing involves practicing with limited resources, such as ready and continuous access to broad-band internet connections (Lindsey, 2007), having little immediately available, on-site multidisciplinary backup (MacKinnon, 2011), and feeling professionally isolated: distant from resources needed for professional practice (Jukkala, Henly, \& Lindeke, 2008; Mills, Birks, \& Hegney, 2010). Scholars have noted that while rural nursing might be described as generalist practice, it demands substantial expertise. Terms such as "extended generalist" (Hegney, 1997, p. 33), "expert generalist" (Bushy, 2002, p. 109), and "multi-skilled generalist" (Kenny \& Duckett, 2003, p. 614; Montour et al., 2009, p. 10) have been employed in attempts to accurately capture the role of rural RNs. Indeed, it has been asserted that rural nursing is specialized practice (Mills et al., 2010), and, according to MacLeod (1998), it is best described as "multi-specialist" practice.

Given the complexity of "multi-specialist" practice, rural nurses require education opportunities to support them in providing the best healthcare possible to rural populations. However, the location and content of existing education programs often make them inaccessible and unsuitable to the context of rural nursing practice (MacLeod, Lindsey, Ulrich, Fulton, \& John, 2008). In British Columbia (BC), Canada, for example, health authorities ${ }^{1}$ attempting to utilize existing specialty education for their rural nurse employees have found that the programs tend to target RNs working in larger, often tertiary, settings (Lindsey, 2007). Research on rural and remote nursing in Canada (MacLeod et al., 2004) and elsewhere (Mbemba, Gagnon, Paré, \& Côté, 2013; World Health Organization, 2010) confirms that locally accessible clinical education relevant to rural practice contributes to job satisfaction and the retention of rural nurses. The sustainability of the rural nursing workforce, therefore, relies to some extent on addressing the learning needs of rural nurses through the provision of education programs that are relevant to the realities of rural nursing practice.

\section{The Rural Nursing Certificate Program}

The "multi-specialist" practice described above is evident in BC where RNs are increasingly working in diverse practice roles within small healthcare facilities in rural communities. In order to address the education requirements of rural RNs, a three-phase pilot project was funded to determine what kind of curriculum should be created and how best to deliver it. The three phases of the pilot project were completed between 2005 and 2010. During Phase 1 (2005-2006), the learning needs of rural RNs across BC were assessed to determine what kind of courses would prepare rural nurses for confident, competent and safe practice. Focus group interviews were conducted with 236 RNs primarily from acute care settings, from 51 rural BC communities, with populations of up to 20,000. Most of these communities have hospitals of between 1 and 100 beds (British Columbia Ministry of Health, 2015).

\footnotetext{
${ }^{1}$ In British Columbia, five regional health authorities govern the delivery of health services in their regions. A provincial health authority works with the regional health authorities to coordinate the delivery of provincial health programs.
} 
The research asked the rural RNs about their everyday practice, their needs for continuing education, appropriate educational delivery methods, and core content required to effectively practice in rural settings. The results of this Phase 1 research confirmed that rural RNs in BC were in need of educational opportunities that were both accessible and relevant to their practice (see MacLeod et al., 2008).

During Phase 2, seven courses were developed that reflected the findings of the Phase 1 research: Health Assessment Across the Lifespan; Chronic Disease Management, Palliative Care and Wound Care; Nursing Practice with Older Persons; Perinatal Care; Critical Care, Emergency and Trauma; Mental Health and Addictions; and, Living and Working in a Rural Community. Course development took place through an innovative team-based approach that partnered course writers with practice experts and academic advisors. The approach of pairing clinical experts with experts in pedagogy ensured that the curriculum remained relevant to rural $\mathrm{RN}$ practice while maintaining academic integrity.

During Phase 3 (2007-2010), the seven courses were implemented as the Rural Nursing Certificate Program (RNCP) ${ }^{2}$ in the University of Northern British Columbia (UNBC) 3 School of Nursing. The RNCP represents the culmination of the three-phase project. It is a provincial program delivering practice-driven curriculum via e-learning modes and practical experiences to RNs in rural communities throughout BC. The UNBC Senate approved the RNCP in June 2007, and as of September 2007, RNCP courses were available as a 30-credit undergraduate nursing certificate that was also transferrable to a post-diploma Bachelor of Science in Nursing. In response to health authority requests, the requirement to take all seven courses was modified, so that RNs could take individual courses. The two most frequently taken individual courses are Perinatal Care and Critical Care, Emergency, and Trauma.

\section{Evaluation}

The intent of the pilot project was to develop a relevant and responsive education program that met the learning needs of rural RNs that would be sustainable over time. Therefore, at the same time that the RNCP curriculum was implemented at UNBC, a formal three-year program evaluation was established to determine whether the learning needs identified in Phase 1 were being met through this specialized education program.

The overall evaluation of the RNCP had both formative and summative components, which aimed to answer questions related to both learning outcomes and program structures and processes. Formative evaluation is an "in-progress" assessment that allows adjustments to be made for the purpose of program enhancement (Patton, 2015). Summative evaluations focus on the outcomes or impacts of a program (Scriven, 1991), and attempt to judge the extent to which goals have been attained (Patton, 2015). The evaluation process was overseen by the Chief Nursing Officers of BC, and facilitated by the program's Implementation and Evaluation Team, composed of rural practice leaders in each of the health authorities and academic leaders within

\footnotetext{
${ }^{2}$ The program was originally named the Rural Acute Care Nursing Certificate (RACNC). However, in response to feedback collected during the developmental evaluation, the name was changed in order reflect its relevance to RNs practicing in areas other than acute care, and the increasing registration in the courses of nurses from community and long term care settings.

${ }^{3}$ The University of Northern British Columbia (UNBC) is located in Prince George (within the Northern Health Authority). UNBC's mission involves addressing the needs of peoples living in rural, remote and northern communities.
} 
the UNBC School of Nursing. This paper focuses on the evaluation of learning outcomes. Specifically, we address the following research question: In what ways has the implementation of this practice-driven model of nursing education influenced nursing practice?

\section{Data Collection and Analysis}

The evaluation focused on whether RN graduates of the RNCP reported increased confidence and competence, and demonstrated current, evidence-informed practice. A qualitative approach (Patton, 2015) was used to get at the depth, detail, and meaning of nurses' and managers' experience of the program and its outcomes. Qualitative data were collected through small group and individual interviews with nurses and their managers. Participants were asked about the benefits and challenges of the program, whether the program impacted nurses' practice, and whether the program affected nurses' job satisfaction. Research ethics approval was obtained from UNBC, as well as from Northern, Interior, Fraser, Vancouver Island, and Vancouver Coastal Health Authorities. All participants received a detailed information sheet and gave consent prior to being interviewed.

The study participants included the first RNCP graduates, nurse managers (of RNCP graduates), and rural RNs who had taken single RNCP courses (rather than the whole program). All RN participants worked in rural settings, were sponsored to take the program by their health authority, and included both new graduate RNs and those with many years of experience. A total of 24 participants, all rural acute care RNs and their managers from BC, were interviewed. Of the 18 initial RNCP graduates, 9 (50\%) agreed to be interviewed, two in a small group interview and seven individually. Five nurse managers agreed to participate in the study with one nurse manager being responsible for two of the RNCP graduates. These nurse managers were interviewed individually. It is important to note that not all of the RNCP graduates had a direct nurse manager who could comment on the RN's nursing practice. Ten individual interviews were conducted with RNs who had taken single courses. Table 1 provides a breakdown of these interviews.

Table 1

Research Participant Interviews

\begin{tabular}{ll}
\hline Participants & Number interviewed \\
\hline RNCP Graduates & 9 \\
Nurse Managers & 5 \\
RNs Taking Single Courses & 10 \\
TOTAL & $\mathbf{2 4}$ \\
\hline
\end{tabular}

Individual and small group interviews were either audio-recorded and transcribed, or extensive notes were taken at the time of the interview. Data were then analyzed in a multi-stage process (Patton, 2015). First, the transcripts or notes were read to gain an understanding of the main messages as a whole. The transcripts/notes were then read individually, paying particular attention to the details and main message of each research respondent. By reviewing the data as a whole, then examining each interview in detail, and continually contrasting the responses from participants, themes began to emerge. Preliminary results were reviewed by practice and 
academic leaders, who were in close touch with RNCP graduates and their managers, to check for (in)congruence of the emerging research themes. Minor refinements resulted from this review.

\section{Findings}

In this section, the themes identified through the analysis of interview data are reported. Interviews with the first RNCP graduates, nurse managers (of RNCP graduates), and rural RNs taking single RNCP courses resulted in findings relating to participants' experiences of the program as a whole, individual courses, and the impact of their education on their practice and work life. The central themes were: 1) impact of learning on practice (e.g., confidence and competence); 2) impact of learning on work life (e.g., leadership role and job satisfaction); and, 3) challenges and barriers (e.g., time management and workload).

\section{Impact of Learning on Practice}

Participants who completed the RNCP, or single courses, made many statements about the overall impact of the program on their practice. In general, the participants reported that their confidence and competence were improved as a result of their education. For example, one RN stated, "It [the RNCP] increased my competence and confidence." Some participants focused on their sense of confidence. One for instance, observed having "much more confidence at work." The participants noted how feeling more confident positively impacted their ability to communicate. One RN described having "increased confidence and better communication with doctors," and continued, "The program gave me confidence and the language to communicate better with them." Similarly, another participant talked about gaining "the language to deal with the doctors, the ability to communicate better with them what I'm seeing in patients."

Rural nurses who completed either the entire RNCP or the individual courses also talked about feeling more competent, and perceived themselves as "better prepared for the workplace" and as doing "a better job." These participants connected their increased competence with having renewed and expanded their nursing knowledge. As one RN commented, "the program has given me the tools to go there, to be competent in my practice." Another RN observed, "my body of knowledge is more broad." One participant specified how his/her skills had improved as a result of the program:

One thing I did learn was to look up and to research what I need to look for. And I have a slightly easier time now if I have a concern to know where to go for the information that I need. [...] So my nursing research is a lot better and knowing where the resource materials are really does make a big difference.

Another made similar comments regarding the impact of gaining knowledge on his/her sense of confidence and competence: "I now have the tools to make the changes that I think need to be made, and I have the knowledge base and I have the confidence."

The nurse manager participants also provided their perspectives regarding the program's effect on RNs' confidence and competence in their practice. One nurse manager made the following observation: "I noticed how-------shows more empowerment, more confidence." Another nurse manager noted how the staff member was "embedding her education into practice." The nurse manger explained, "some nurses take courses but it doesn't change practice." Several nurse managers commented on how staff members who had completed the program were thinking differently, more broadly, and with more awareness. For example, one 
remarked, "it opened [the RN's] eyes to what she can do locally, broadened her perspective" while another described how the RN was "bringing it all together," and that his/her "thinking and analysis are very different, in a big way." A nurse manager summarized how the sense of confidence and improved competence had impacted his/her staff member, stating that she "takes more responsibility, takes leadership with good physician support and clinical support, she is the 'go to person'."

In addition to these perspectives on the program as a whole, RNs also remarked on specific courses within the program, and the impact of each course on their practice. One participant stated, "I can honestly say that they were all great courses in their own way. I certainly got something out of all of them. I was really able to pull so much information out of all of that, that I will be able to use throughout the rest of my nursing career." Table 2 provides an example for each course of how it impacted practice.

Table 2

Examples of RN Feedback for each RNCP Course

Health Assessment \& RN First Call:

"... one of the tests I learned when we were going over the hands-on - making up our health assessment sheets - it's impacted the way I teach my preceptees, how I teach new grads when they're coming on. It's changed my practice. I do a lot more specific testing. I don't always have a doctor on hand. I had a compression fracture in the spine [and] I was able to do some of the straight leg tests, some of the different exams that I hadn't done before. I've added to my repertoire of how to do an assessment, and I feel more comfortable, I feel I am doing a more thorough assessment. It opened my eyes to better assessment."

Chronic Disease Management, Palliative \& Wound Care:

"I knew I wanted palliative care and wound care, they are really important to me in my work. But it was the acute versus chronic care that got me thinking and moving in this direction. I didn't expect this. I did a lot more research in chronic disease management to understand what I could do personally in practice. One person can make a difference. I learned there is this body of research all around you, all around the world looking at these issues, now I feel not so alone. Chronic Disease Management spoke volumes to me."

Nursing Practice With Older Persons:
"The nursing practice of the elderly, that one blew me away, that course. I was profoundly
impacted by it because it impacts so much of our population, our practice with the elderly. When
I see a resident in crisis the first thing I think of is delirium. I mean, we used to just say 'they're
sun-downing'. Well no, they are not sun-downing, they're a medical emergency."
Perinatal Care:
"For my Maternity, we had to do a big project, and what I did was like a paint-by-numbers
delivery and we've got that with the maternity bundle because lots of times people show up and
they're in labour, right, and you can't transport them because they're too far along and we don't
normally do deliveries here. So, I think the whole facility benefited from me going through this
program because I brought a lot of things there. When somebody is a certain amount of
centimeters it is easier to deliver them in a hospital than in the back of an ambulance, and that is


what happened several times before, the person delivered half way between ----- and ------ which shouldn't happen. That was sort of our thing - 'Oh God, get them out of here' - and now it's 'no, what's safest for mom and babe",

Critical Care, Emergency, \& Trauma:

A woman came in to emergency presenting with "GI problems, diarrhea, stomach pains." This RNCP graduate explained that the patient then began to complain of chest tightness and a painful arm. She consulted with a colleague who thought the problem was insignificant, but the RNCP graduate assessed the situation differently. She remembered from her course that women often present differently. She put the ECG leads on the patient and began to read the cardiac rhythm. She explained, "I could see something was wrong, the spaces were wrong in the QRS." Although this nurse could not diagnose the problem she recognized the emergency. She called the doctor and reported what she was seeing on the ECG. The doctor came in immediately just as the woman was going into cardiac arrest. "I have put a lot of learning into practice, and I have much more confidence. I know the meds, the routine of cardiac arrest, I remembered, I know what to expect. I know that cardiac arrhythmias are very important." In addition, this nurse went to the cardiac catheter laboratory as part of her practicum experience. She is now able to explain the procedure to clients and better prepare them for what they might expect.

\begin{abstract}
Mental Health \& Addictions:
"I don't deal with mental health often, but I do know that after I took the course there was a young man who came in with his mother. He's a known schizophrenic and I just really made an effort to apply what I had learned to the patient. His mother brought him in but he's an adult in his late 30s. I talked to him, not his mother, and you know who I really made a big difference with was his mom. She was so appreciative. When she left she said 'I want to thank you very much.' And I know it was because I am sure that he's sort of ignored when there's a problem and they talk through his mom. But she was very responsive to me and I made eye contact with him and I was not judgmental. He had to end up going to ------- and I made all the arrangements and then told him what the arrangements were and I remember I just made a real effort to show the respect for him that he deserved instead of putting that label of schizophrenic on him. I think mental health tends to frighten people that aren't around it all the time because the patients can be so volatile and you just don't know what to expect or whatever, but I remember thinking 'I am really going to put my learning into practice here.' The whole course made me more aware and I think the discussion groups were very, very good about how we do that labeling and we do that judgment and how it is the non-verbal and that sort of stuff that sets people off, or can be perceived. She (the instructor) said "people will forget what you said and they will forget what you did but they will never forget how you made them feel.'”
\end{abstract}

Living \& Working in a Rural Community:

"Taking this course was very important: it broadened my understanding of First Nations communities better." This RNCP graduate gave an example of working in emergency and being more responsive to First Nations individuals' needs. "There is a residential school two miles away, I used to think it was wonderful, but now I realize how awful it was. I have a better understanding of where they are at, what experiences they had." 


\section{Impact of Learning on Work Life}

Participating RNs spoke about the ways in which their experience in the program affected their work life. Overwhelmingly, the participants' learning experiences reignited a passion for nursing. For example, one RN stated, "I have a new found interest in things that I didn't realize I had." Another provided the following detailed explanation:

It [the RNCP] has recaptured this spark in my interest in nursing. I think after you've been in nursing awhile you sort of become complacent about things. The whole way it was set up that you had discussions online, and then you had the workshops and stuff, it was great to be around similar people because you don't get that in rural nursing. You know, from other areas to discuss, how you can improve things, or, you know, how somebody's dealt with this that's come up before, or whatever. I found it really valuable.

Yet another participant talked about how his/her love of nursing expanded following his/her involvement in the program:

I've always loved my job. I love maternity and now I realize I love seniors, too. You know, I never dreamed I would and I love the chronic disease part of it all, and I love the patient part. It's like having a whole greater look at how things actually work."

Several RN participants described how their experience in the RNCP led to them taking on leadership roles. One participant stated, "I moved into a leadership role half way through the program. There were two candidates; I got the position." Another RN said, "I am now a clinical lead." As one participant observed, "if I hadn't taken this program, I probably wouldn't have become the clinical lead of Emerg and multi-level care." Participants also talked about how the program inspired them to be role models. For instance, one RN talked about having a "passion to be a better role model." Likewise, another stated, "I always preceptor students through here, but it [the RNCP] just gave me more of a passion to be a better role model and teacher for them." Still another made the following comment: "I now do mentoring, coaching, and looking beyond the walls of the hospital. I try to be a role model."

In a similar vein, several RNs talked about taking greater initiative in terms of mentoring and teaching following the program. As one participant explained, "I've always done the teaching, I just do a better job now. It's just I've got a lot more that I can offer. It's [the RNCP] given me more tools to teach with." Another RN commented on the program's impact on his/her teaching role: "We have in-service on Wednesday and I have to admit that since taking the course [the RNCP] it has just sparked me to make learning for them more interesting and get more things going and make sure that they get opportunities for training and for doing new things and not just with me being the teacher." Participants who had teaching duties often shared the knowledge they gained from the RNCP courses. One participant described how doing this was positive for the other nurses he/she worked with:

I have done a lot in our emergency department to bring everybody up to speed on things like teaching so everybody has better tools to deal with emergencies. I think I have made a lot of nurses feel a lot more comfortable when someone comes in. We have things in place. They don't feel like 'Oh my God, I don't know what to do,' just waiting around fretting until the doctor comes. 
Another common theme emerging from the interview data was that RNs experienced their range of practice expanding following the program. Some participants expanded their roles in their current areas. One stated, "I will now go to emergency in an expanded role" while another said, "I have expanded my role into chronic disease management." Other participants found that they were able to move into practice areas that they had not previously been working in. For example, one RN explained, "I always worked maternity, but since taking the critical care course I am working also in Emerg. It gives me greater variety."

Finally, RN participants felt that the RNCP had resulted in an overall increase in their job satisfaction. As one participant stated, "I love my job and it [the RNCP] definitely has enhanced it." For another RN, the increased job satisfaction he/she experienced was due to the knowledge gained during the RNCP: "The knowledge from this program has broadened my sense of nursing as a whole. I am proud to be a nurse. It is wonderful to work in the hospital and community." According to several RNs, the increase in confidence and competence they experienced with respect to their practice translated into increased job satisfaction. As one participant stated:

For me, job satisfaction comes out of confidence in my practice. Yes, definitely it [the RNCP] did increase my job satisfaction because I have the education and the experience to back it up. I feel more comfortable and confident.

Some RNs talked about being better able to contribute to the health care team. For example, a participant said, "the stress level is high in rural sites, and now I have more ability to be part of the team and respected for my knowledge and skills" while another stated, "since I started [the RNCP] the job satisfaction and my abilities to be part of the health care team has increased significantly." Another perspective expressed by participants was that the program itself represented an increased awareness of, and respect for, rural nurses. As one RN explained, "It [the RNCP] also lifted the role of the rural nurse. When I came here I was very amazed how generally people look down at rural nurses." Similarly, another participant stated, "job satisfaction also comes from knowing that the government is recognizing the need for rural education." Some participants described how they had become "frustrated" or "stagnant" with respect to their work, and how the program had helped to address that frustration, thereby increasing job satisfaction:

It opens doors and it opens knowledge to just kind of personally grow. So instead of becoming a frustrated person in my job, rather to say there is a time and there is a way out and I can move or I can go somewhere else. I think in the end that's what keeps my job satisfaction and my positive attitude.

As one RN summed up, "I was burned out, stagnant. Now I have more job satisfaction."

\section{Challenges and Barriers}

While much of the feedback provided by participants was positive, the interviews also elicited comments related to challenges and barriers. The most common challenge mentioned was time management. According to RNs, the challenge to manage time was related, in part, to the heavy workload of the program. One participant stated, "I found sometimes the workload a bit heavy." Others found the workload "unmanageable." As one RN observed, "It was making me literally physically sick." Another was similarly emphatic: "We were just overwhelmed with work. It was at the point where I was actually going to quit." It is important to consider the context in which many of the RNs were taking the program. The RNs were often married with 
children, frequently worked full-time, or had more than one part-time position. Participants reported that they regularly had to work overtime, leaving little time for study. They experienced significant challenges around coordinating their lives to give adequate attention to their work, their home and family, and to their studies. As one participant explained:

I found the workload heavy and I can't imagine how people work full time, because I was only working half time. I guess it's just that you have to set your priorities because I have three children involved in sport. You know, being involved in family as well, there's a lot of pressures. Finding the time, if not a barrier, it was certainly an obstacle.

Another participant concurred that time management was affected by the competing demands of work and family: "It [the RNCP] was demanding so time management would be huge and also be mentally prepared because it is being an adult learner and carrying on your fulltime work and being a parent, etc." In addition, several participants felt that university course requirements and assignments lacked flexibility and required them to adhere to "relentless deadlines." Indeed, some participants found it difficult to get time off work to attend course workshops or practicum experiences. Managers noted that it was difficult to arrange for coverage for the RNs while they took the program. As one manager said, "practicums are very challenging".

Adjusting to online learning was another challenge. Some participants reported feeling uncomfortable and unfamiliar with computer use and online learning, particularly when they started the program. As one RN observed, it "took a lot of my time trying to figure out how to get the computer to work and to do Moodle [online learning system]." Another explained, "learning the computer was huge for me. It would say 'cut and paste' and I looked at my 12 year old, what do they mean? I was thankful I had teenagers here to help me." However, participants also commented on the support provided through the program. For example, one participant stated, "the technical support was just fabulous." As the RNs gained more experience with computers, online learning was seen less as a barrier and more as an opportunity: "I think honestly for the most part that the style of teaching that went on via the Internet - because it was all for the most part done by the Internet - was impressive." Slow Internet connections in some communities remained a challenge for a few RNs who lived in more remote areas.

While most participants stated that the RNCP was relevant to their rural practice, there were a few who thought that lack of relevance was a barrier. First, participants felt that the course, Living and Working in a Rural Community, did not adequately address their learning needs. For example, one RN explained that, in her view, the course did not teach anything new to those who already lived and worked in a rural community: "It was like you're trying to take a city person and teach them about rural." Another participant stated: "I thought Living and Working in a Rural Community was, not really a waste of time, but it was like that's what we're really doing, right? Living and working!" Participants tended to speak positively about the Aboriginal component of Living and Working in a Rural Community, but expressed negative opinions about the rest of the course's content. For example, one RN stated, "the Aboriginal component I though was really excellent; the other part I really was sort of dubious about it" while another explained, "I actually wish that the Aboriginal part was more of that course. I didn't feel like we got enough of that. The first half of that course I found I had done it, we had done it, we were living it." However, another RN suggested that the Aboriginal component of Living and Working in a Rural Community "could've been a lot more practice related." 
Second, a RN participant and a nurse manager raised the issue of whether the program was relevant to nurses working at larger rural sites. ${ }^{4}$ For example, a nurse manager commented, "this program isn't as important for larger sites, we still need ---- [the name of a post-secondary institution that offers specialty certifications]." This concern was largely due to confusion around single courses. While the program as a whole was considered a rural specialty, taking a single course - for example, Critical Care, Emergency and Trauma - was not equivalent to taking a specialty certification on that topic (i.e., critical care). One participant talked about the misunderstanding that single courses were equivalent to specialties (e.g., that taking Perinatal Care was equivalent to completing a specialty certification in maternity). This participant stated, "When we took the maternity course with ---- there were a couple of the employers that felt that these [RNs] were now prepared to work on maternity, right? And it is not - it is a stepping stone - and it is not a specialty, that what you're learning does not make you a specialist in any of those areas for that." For one nurse manager at a larger rural site, "the RNCP is not intense enough for critical care and maternity." The diversity among rural communities and rural health care settings is great. Therefore, nurses and nurse managers at larger rural sites who were interested in specialty certifications in areas other than rural nursing (i.e., critical care or maternity) may have found that the RNCP fell short.

\section{Outcomes of the Pilot}

Over the course of the three years of the pilot, a total of 226 RNs from 77 communities completed courses in the RNCP. The RNs were primarily from the five BC health authorities, with a few from the Yukon and the Northwest Territories. The evaluation feedback was used to modify some course content and delivery modes. For example, the content and assignments of the course, Living and Working in a Rural Community were reviewed and revised to make them more pertinent. The challenges for some nurses of getting away to the workshops and clinical practica were addressed in two ways. The health authorities re-examined how to back-fill or adjust shifts to assist RNs to get to workshops and clinical practica. At the same time, UNBC worked with the health authorities to offer the workshops in several locations across the province, using local clinical experts working together with the course faculty, so that RNs did not need to travel as far.

The pilot demonstrated both what was important in the RNCP and what was needed to ensure the program's sustainability. The Chief Nursing Officers of BC, with UNBC, were successful in obtaining ongoing funding from the Ministry of Advanced Education for the RNCP at UNBC. In response to the health authorities' needs for new graduate RNs with better preparation in rural practice, the courses have been integrated with pre-registration undergraduate education at UNBC (Zimmer et al., 2014). Although other programs have started in Canada (see Kulig, Kilpatrick, Moffitt, \& Zimmer, 2013), the RNCP remains the only rural nursing certificate program in the country.

\section{Discussion}

Gaining and maintaining nursing competency in rural nursing practice, though critically important, is not easy, given the range of knowledge needed and the challenges for rural nurses in accessing continuing education. Competent, confident RNs are critical to ensure high quality

\footnotetext{
${ }^{4}$ There is a great deal of diversity among rural hospitals in BC. For example, rural hospitals in Northern Health range from 5 to 55 acute care beds.
} 
patient care in rural settings. Indeed, as Jukkala et al. (2008) state, "skillful and knowledgeable health care providers decrease liability and increase consumer confidence in local health care services" (p. 562). In rural and remote communities, however, nurses face barriers to learning opportunities (Jukkala et al., 2008; Penz et al., 2007). Most education programs are located in urban areas and designed to meet the needs of urban nursing practice making them inaccessible and irrelevant to rural nurses (Jukkala et al., 2008). The design of the RNCP, particularly its accessibility, relevance, and responsiveness helped to build capacity in rural communities, an important concern for rural continuing education (Habjan, Kortes-Miller, Kelley, Sullivan, \& Pisco, 2012).

The RNCP's outcomes were in keeping with Kulig's (2005) call for nursing programs to prepare rural nurses, "not only with solid, relevant knowledge and skills, but also with skills at linking with community resources and finding answers on their own because they so often have to work alone" (p. 1). Participants gave concrete and compelling examples of how their levels of confidence and competence rose as a result of their education. Evidence obtained from both nurses and their managers also indicated that those RNs taking RNCP courses improved their practice, increased their knowledge, and developed important skills around research and evidence, effective communication, and teamwork. This important finding confirms that education for rural nurses, such as that provided by the RNCP, is "an integral part of maintaining a highly competent nursing work force in Canada" (Penz et al., 2007, p. 58). Our research has shown that the RNCP largely succeeded in providing opportunities for gaining confidence and competence.

In addition to raising their levels of competence and confidence, RNs reported that their participation in the RNCP expanded their opportunities and increased their overall job satisfaction. Participants talked about gaining a sense of pride in their rural practice following the program. They became mentors and teachers, often feeling inspired to put extra effort into supporting other nurses at their sites. This positive outcome of the RNCP reflects other scholarship that links relevant, accessible education opportunities for rural nurses with enhanced job satisfaction (see, for example, Andrews et al., 2005; Levett-Jones, 2005; World Health Organization, 2010) and positive professional environments (Buykx, Humphreys, Wakerman, \& Pashen, 2010). Both job satisfaction and positive professional environments contribute to retaining RNs, which is a critical concern in rural areas where nursing shortages have become chronic.

Participants also experienced challenges while in the RNCP, the most significant being time-management and workload. Penz et al. (2007) note that life situation factors, such as having dependent children and full-time employment, negatively affect nurses' perceptions of barriers to education. In addition, rural nurses face greater time constraints, often due to the nature of their practice. For example, nurses in rural practice settings work alone or with few colleagues, making time off to study or attend workshops next to impossible (Andrews et al., 2005). As Penz et al. (2007) argue, "[i]t is not realistic to expect nurses who work shifts, are employed full-time, have dependent children or relatives, are without a partner, and live in isolated areas to travel and pay for the expenses for CE [continuing education] activities" (p. 65). Therefore, while acknowledging the complexity of these issues, Penz et al. (2007) call upon governments and employers of rural nurses to provide better support for rural nursing education. It is noteworthy that although RNs were sponsored by the health authorities to take the RNCP, including covering their educational and travel costs, the nurses and their managers often found it difficult to arrange 
for time away from the clinical setting. The limited staffing in many rural facilities made it challenging for the RNs to attend workshops and clinical practicum experiences in larger centres, as well as to have protected study time.

\section{Limitations}

This study relies on RNs self-assessing their experiences in the program, as well as the impacts of the program on their practice. By including their nurse managers, we were able to provide some triangulation of the RNs' self-assessments. However, one important tension remains; this research was unable to comment on whether the program had a positive effect on patient outcomes. We suggest that this is an important area for further research, and that findings would provide substantial direction for policy in the area of rural nursing education.

The RNCP was specifically designed to meet the needs of RNs working in rural acute care facilities. Over the course of the pilot, it was acknowledged that nurses in other rural facilities (e.g., community health, home care, residential care), and in remote communities could benefit from the courses. Further research is needed on the suitability of RNCP courses for RNs in these other settings.

\section{Conclusion}

Nurses who participated in the RNCP provided positive feedback regarding their competence, confidence, and job satisfaction. Such outcomes bode well for supporting recruitment and retention efforts, and for the development of capacity within rural healthcare facilities. Such development has the potential to improve patient outcomes. Relevant, accessible education will assist organizations in their efforts to create supportive professional practice environments and to effectively recruit and retain rural nurses. The RNCP has the potential to make a significant contribution towards improving recruitment and retention of nurses in rural communities. Given the health disparities experienced by rural residents when compared to their urban counterparts, and given the continuing shortage of health care workers in rural and remote regions, the importance of rural-relevant, accessible education cannot be underestimated. 


\section{References}

Andrews, M. E., Stewart, N. J., Pitblado, J. R., Morgan, D. G., Forbes, D., \& D’Arcy, C. (2005). Registered nurses working alone in rural and remote Canada. Canadian Journal of Nursing Research, 37(1), 14-33.

British Columbia Ministry of Health. (2015). Rural health services in BC: A policy framework to provide a system of quality care. Victoria, BC: Ministry of Health. Retrieved from http://www.health.gov.bc.ca/library/publications/year/2015/rural-health-policy-paper.pdf

Bushy, A. (2002). International perspectives on rural nursing: Australia, Canada, USA. Australian Journal of Rural Health, 10(2), 104-111. doi:10.1046/j.14401584.2002.00457.x

Buykx, P., Humphreys, J., Wakerman, J., \& Pashen, D. (2010). Systematic review of effective retention incentives for health workers in rural and remote areas: Towards evidencebased policy. Australian Journal of Rural Health, 18, 102-109. doi:10.1111/j.14401584.2010.01139.x

Habjan, S., Kortes-Miller, K., Kelley, M. L., Sullivan, H., \& Pisco, L. (2012). Building capacity in rural health services: The effect of continuing education. In Kulig, J. C. \& Williams, A. M. (Eds.). Health in rural Canada. Vancouver, BC: University of British Columbia Press.

Hegney, D. (1997). Rural nursing practice. In L. H. Siegloff (Ed.), Rural nursing in the Australian context. Canberra, Australian Capital Territory, Australia: Royal College of Nursing.

Jukkala, A. M., Henly, S. J., \& Lindeke, L. L. (2008). Rural perceptions of continuing professional education. The Journal of Continuing Education in Nursing, 39(12), 555563. doi:10.3928/00220124-20081201-08

Kenny, A. \& Duckett, S. (2003). Educating for rural nursing practice. Journal of Advanced Nursing, 44(6), 613-622. doi:10.1046/j.0309-2402.2003.02851.x

Kulig, J. (2005). Factsheet 2: What educational preparation do nurses need for practice in rural and remote Canada? The Nature of Rural and Remote Nursing, 2. Prince George, BC: UNBC. Retrieved from http://ruralnursing.unbc.ca

Kulig, J., Kilpatrick, K., Moffitt, P., \& Zimmer, L. (2013). Rural and remote nursing practice: An updated documentary analysis. Lethbridge: University of Lethbridge. RRN2-02. Retrieved from http://ruralnursing.unbc.ca

Levett-Jones, T. L. (2005). Continuing education for nurses: A necessity or nicety? The Journal of Continuing Education in Nursing, 36(5), 229-233. doi:10.3928/0022-0124-2005090110

Lindsey, A. E. (2007). Rural focused nursing education: Post-basic nursing specialty education in northern and rural British Columbia. Phase 2 Report. Prince George, BC: Northern Health.

MacKinnon, K. (2011). Rural nurses' safeguarding work: Reembodying patient safety. Advances in Nursing Science, 34(2), 119-129. doi:10.1097/ANS.0b013e3182186b86

MacLeod, M. (1998). We're it: The nature of nursing practice in very small rural and remote hospitals in northern $B C$. Prince George: UNBC.

MacLeod, M., Kulig, J., Stewart, N., \& Pitblado, R. (2004). Nursing practice in rural and remote Canada: Final report to Canadian Health Services Research Foundation. Prince George, BC: University of Northern BC. Retrieved from http://ruralnursing.unbc.ca 
MacLeod, M. L. P., Lindsey, A. E., Ulrich, C. H., Fulton, T., \& John, N. (2008). The development of a practice-driven, reality-based program for rural acute care registered nurses. The Journal of Continuing Education in Nursing, 39(7), 298-304. doi:10.3928/00220124-20080701-03

MacLeod, M. L. P. \& Zimmer, L. V. (2005). Rethinking emancipation and empowerment in action research: Lessons from small rural hospitals. Canadian Journal of Nursing Research, 37(1), 68-84.

Mbemba, G., Gagnon, M-P., Paré G., \& Côté, J. (2013). Interventions for supporting nurse retention in rural and remote areas: An umbrella review. Human Resources for Health, 11, 44. doi:10.1186/1478-4491-11-44.

Mills, J., Birks, M., \& Hegney, D. (2010). The status of rural nursing in Australia: 12 years on. Collegian, 17(1), 30-37. http://dx.doi.org/10.1016/j.colegn.2009.09.001

Montour A., Baumann, A., Blythe, J., Hunsberger, M. (2009). The changing nature of nursing work in rural and small community hospitals. Rural Remote Health, 9, 1089.

Patton, M.Q. (2015). Qualitative research and evaluation methods (4th ed.). Thousand Oaks, CA: Sage.

Penz, K., D’Arcy, C., Stewart, N., Kosteniuk, J., Morgan, D., \& Smith, B. (2007). Barriers to participation in continuing education activities among rural and remote nurses. The Journal of Continuing Education in Nursing, 38(2), 58-66. doi:10.3928/0022012420070301-03

Scriven, M. (1991). Beyond formative and summative evaluation. In M. W. McLaughlin \& D. C. Phillips (Eds.) Using program theory in evaluation, New Directions for Program Evaluation Series, No. 33, 59-76. Jossey-Bass, San Franscisco.

World Health Organization. (2010). Increasing access to health workers in remote and rural areas through improved retention. Geneva: WHO.

Zimmer, L.V., Banner, D., Aldiabat, K., Keeler, G., Klepetar, A., Ouellette, H., Wilson, E., \& MacLeod, M. (2014). Nursing education for rural and northern practice in Canada. Journal of Nursing Education and Practice, 4(8), 162-172. doi:10.5430/jnep.v4n8p162 